\title{
Liberal versus restrictive red blood cell transfusion strategy in sepsis or septic shock: a systematic review and meta- analysis of randomized trials
}

Yohei Hirano* (D), Yukari Miyoshi, Yutaka Kondo, Ken Okamoto and Hiroshi Tanaka

\begin{abstract}
Background: We assessed the effect of liberal versus restrictive red blood cell transfusion strategy on survival outcome in sepsis or septic shock by systematically reviewing the literature and synthesizing evidence from randomized controlled trials (RCTs).
\end{abstract}

Methods: We searched the MEDLINE, Cochrane Central Register of Controlled Trials, and Web of Science databases. We included RCTs that compared mortality between a liberal transfusion strategy with a hemoglobin threshold of 9 or $10 \mathrm{~g} / \mathrm{dL}$ and a restrictive transfusion strategy with a hemoglobin threshold of $7 \mathrm{~g} / \mathrm{dL}$ in adults with sepsis or septic shock. Two investigators independently screened citations and conducted data extraction. The primary outcome was 28- or 30-day mortality. Secondary outcomes were 60- and 90-day mortality, use of life support at 28 days of admission, and number of patients transfused during their intensive care unit stay. DerSimonian-Laird random-effects models were used to report pooled odds ratios (ORs).

Results: A total of 1516 patients from three RCTs were included; 749 were randomly assigned to the liberal transfusion group and 767 to the restrictive strategy group. Within 28-30 days, 273 patients (36.4\%) died in the liberal transfusion group, while 278 (36.2\%) died in the restrictive transfusion group (pooled OR, 0.99; 95\% confidence interval $[\mathrm{Cl}], 0.67-1.46)$. For the primary outcome, heterogeneity was observed among the studies $\left(P^{2}=\right.$ $61.0 \%, x^{2}=5.13, p=0.08$ ). For secondary outcomes, only two RCTs were included. There were no significant differences in secondary outcomes between the two groups.

Conclusions: We could not show any difference in 28- or 30-day mortality between the liberal and restrictive transfusion strategies in sepsis or septic shock patients by meta-analysis of RCTs. Our results should be interpreted with caution due to the existence of heterogeneity. As sepsis complicates a potentially wide range of underlying diseases, further trials in carefully selected populations are anticipated.

Trial registration: This present study was registered in the PROSPERO database (CRD42018108578).

Keywords: Sepsis, Septic shock, Transfusion, Hemoglobin, Threshold, Mortality

\footnotetext{
* Correspondence: yhirano@juntendo-urayasu.jp

Department of Emergency and Critical Care Medicine, Juntendo University

Urayasu Hospital, 2-1-1 Tomioka, Urayasu, Chiba 279-0021, Japan
}

(c) The Author(s). 2019 Open Access This article is distributed under the terms of the Creative Commons Attribution 4.0 International License (http://creativecommons.org/licenses/by/4.0/), which permits unrestricted use, distribution, and reproduction in any medium, provided you give appropriate credit to the original author(s) and the source, provide a link to the Creative Commons license, and indicate if changes were made. The Creative Commons Public Domain Dedication waiver (http://creativecommons.org/publicdomain/zero/1.0/) applies to the data made available in this article, unless otherwise stated. 


\section{Background}

Patients with sepsis or septic shock are often anemic and undergo red blood cell (RBC) transfusion. This intervention may restore the balance between oxygen supply and demand by increasing oxygen delivery into tissue $[1,2]$. However, RBC transfusion may also lead to deleterious events such as cardiovascular overload, acute kidney injury, acute lung injury, infectious complications, and immunomodulation [3-5]. With these adverse effects of RBC transfusion, clinicians are challenged with selecting the optimal threshold of transfusion for sepsis patients to improve survival outcome.

Two different strategies of RBC transfusion ("liberal" transfusion with a hemoglobin threshold of 9 or $10 \mathrm{~g} / \mathrm{dL}$ and "restrictive" transfusion with a hemoglobin threshold of $7 \mathrm{~g} / \mathrm{dL}$ ) have been compared in observational studies and a few randomized controlled trials (RCTs) to assess which strategy would be more beneficial in treating sepsis patients [6]. After the introduction of the systematic review process, the newest international guidelines for the management of sepsis and septic shock (Surviving Sepsis Campaign, 2016) recommended restrictive $\mathrm{RBC}$ transfusions only when the hemoglobin level decreases to $<7.0 \mathrm{~g} / \mathrm{dL}$ in adult sepsis in the absence of extenuating circumstances, such as myocardial ischemia, severe hypoxemia, or acute hemorrhage [7]. However, this recommendation is based on limited data from only two clinical trials, including one less-direct assessment of blood transfusion therapy $[8,9]$.

Until now, there has been no meta-analysis reviewing only RCTs on hemoglobin threshold for RBC transfusion in sepsis. Therefore, we aimed to conduct a systematic review and meta-analysis of present RCTs to assess the effect of liberal versus restrictive RBC transfusion strategy on survival outcome in sepsis or septic shock patients.

\section{Methods}

Data sources and search strategies

To identify eligible trials, we searched the Cochrane Central Register of Controlled Trials, the MEDLINE, and the Web of Science databases on June 21, 2018. Searches were not restricted by publication status, publication date, and sample size. We did not search references of articles. The search terms used were "(sepsis OR septic shock) AND (transfusion OR transfused OR transfusions OR hemoglobin) AND (randomised OR randomized)".

\section{Study selection}

Titles and abstracts of references were retrieved from the databases. After all duplicate studies were excluded, two investigators ( $\mathrm{YH}$ and $\mathrm{YM}$ ) independently screened the titles and abstracts for eligibility. When a disagreement was identified between reviewers, the full text of the article was obtained to determine the study's eligibility, and differences in opinion were resolved by consensus. If disagreements could not be reconciled, a third investigator (YK) was consulted. The full texts of articles included in the final selection were independently reviewed by two investigators ( $\mathrm{YH}$ and $\mathrm{YM}$ ). Finally, eligible studies were determined after discussion and resolution of discrepancies by consensus.

We identified the studies to be included by following a research question formulated according to the participants, interventions, comparisons, and outcomes (PICO) model, as follows: P, adult ( $\geq 18$ year old) patients admitted to the intensive care unit (ICU) with a diagnosis of sepsis or septic shock; I, liberal RBC transfusion strategy (blood transfusion with a hemoglobin threshold of $\leq 9$ $10 \mathrm{~g} / \mathrm{dL}$ ); C, restrictive RBC transfusion strategy (blood transfusion with a hemoglobin threshold of $\leq 7 \mathrm{~g} / \mathrm{dL}$; and $\mathrm{O}$, all-cause mortality. We did not restrict the definition of sepsis to the latest definition [10]; instead, we allowed all past definitions of sepsis when identifying the studies to be included.

\section{Data extraction}

Data were extracted independently by two investigators, and consensus was reached. The data extracted included the following: author, publication year, country, study design, number and type of participants, severity and source of sepsis, timing of randomization, duration of intervention, trial exclusion criteria, inclusion period, hemoglobin threshold, leukodepletion of blood transfused, outcome measures, and study results.

\section{Study endpoints}

We set short-term mortality defined as 28- or 30-day mortality as the primary outcome. The secondary outcomes were 60- and 90-day mortality, use of life support (ventilation, vasopressor use, or renal replacement therapy [RRT]) at 28 days of admission, and number of patients transfused during their ICU stay.

\section{Assessment of methodological quality}

We adapted the Cochrane risk-of-bias tool to assess the quality of the studies included for meta-analysis [11]. Two investigators ( $\mathrm{YH}$ and $\mathrm{YM})$ independently assessed the risk of bias of the included studies, and a third investigator (YK) resolved the discrepancies using an independent blinded evaluation. Additionally, we graded the quality of evidence of each finding based on the criteria established by the Grading of Recommendations Assessment, Development and Evaluation (GRADE) working group [12]. The quality of the study methodology was independently classified by the two investigators as high, intermediate, low, or very low, based on study design, 
risk of bias, indirectness, inconsistency, imprecision, and publication bias. The publication biases were assessed visually by inspecting funnel plots as well as analytical appraisals based on Egger's linear regression test [13]. A two-sided $p$ value of $\leq 0.10$ was regarded as significant in Egger's linear regression test.

\section{Statistical analysis}

We pooled the eligible patients for each outcome and calculated the odds ratios (ORs) and corresponding 95\% confidence intervals (CIs) using the DerSimonian-Laird random-effects model with weights calculated using the inverse variance method. We verified the heterogeneity of the studies using the Cochran chi-squared, tausquared, and $I^{2}$ statistics $\left(I^{2}>50 \%\right.$ was considered a measure of severe heterogeneity). We applied unadjusted $p$ values for the significance assessment in this study, which were set at the two-tailed 0.05 level for hypothesis testing and at the 0.10 level for heterogeneity testing. All statistical analyses were performed using the Cochrane systematic review software Review Manger version 5.3.5 for Windows (The Nordic Cochrane Centre, the Cochrane Collaboration, Copenhagen, Denmark), except for the analysis of publication bias, which was through Stata version $15 \mathrm{SE}^{\circ}$ (StataCorp LP, 2013).

\section{Results}

\section{Search results}

We identified 1040 studies from the electronic databases after elimination of duplicates. Among them, only 14 studies were eligible based on the assessment of the title and abstract. After review of their full-text articles, 11 studies were excluded because they were reviews or the same trials reported in the other studies included, they were conducted with a different study design or outcome, or they involved an inappropriate cohort. Finally, three RCTs were included in this meta-analysis $[8,14$, 15] (Fig. 1).

\section{Study characteristics}

We analyzed a total of 1516 patients from the three RCTs, namely TRICOP, TRISS, and TRICC. Among them, 749 patients were randomly assigned to the liberal transfusion group and 767 to the restrictive transfusion group. Two of the three studies were multicentric studies (TRISS and TRICC). Participants in the TRISS study

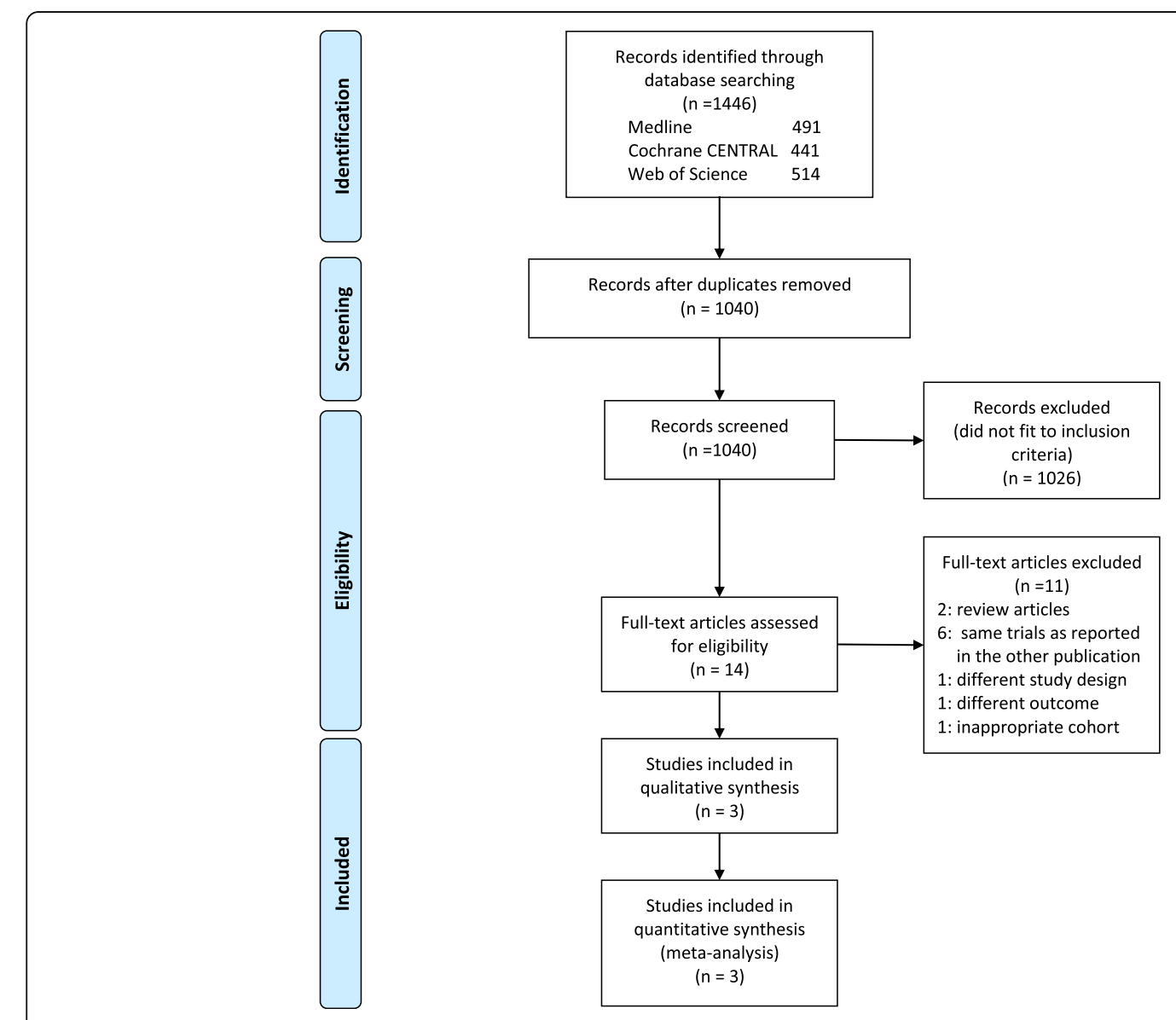

Fig. 1 Flow diagram of search strategy and study selection 
were patients with septic shock, while those in the TRICOP study were cancer patients with septic shock. In the TRICC study, the participants were critically ill patients and not restricted to sepsis patients. However, a subgroup analysis was performed for patients with severe infection or septic shock. Although lungs were the most frequent cause of sepsis in the TRICOP and TRISS trials, there was a diversity in the source of infection among studies. All trials excluded patients with uncontrolled bleeding or the withdrawal from active therapy. However, there were a variety in exclusion criteria among studies, represented by acute myocardial ischemia which was only excluded in the TRISS trial. In all studies, RBCs were transfused when the hemoglobin level was $<7 \mathrm{~g} / \mathrm{dL}$ for restrictive strategy. The hemoglobin threshold for liberal transfusion was set at $<9 \mathrm{~g} / \mathrm{dL}$ in the TRISS and TRICOP trials, and at $<10 \mathrm{~g} /$ $\mathrm{dL}$ in the TRICC trial. All RBC units were leukodepleted in two of the three studies (TRICOP and TRISS). The individual characteristics of the three RCTs are detailed in Table 1.

\section{Outcome}

The forest plot of the primary outcome is shown in Fig. 2. Within 28-30 hospital days, 273 of 749 patients (36.4\%) died in the liberal transfusion group, while 278 of 767 patients $(36.2 \%)$ died in the restrictive transfusion group. There was no difference in 28- or 30-day mortality between the two transfusion strategies (pooled OR, 0.99; $95 \% \mathrm{CI}, 0.67-1.46$ ). In the evaluation of secondary outcomes, only two RCTs (TRICOP and TRISS) were included because we could not obtain any information about the outcomes other than 30-day mortality from the subgroup analysis of patients with severe infection or septic shock in the TRICC study. Similar to 28- or 30 -day mortality, there were no significant differences in 60 - or 90-day mortality between the liberal and restrictive transfusion strategies (pooled OR, 0.91 [95\% CI, $0.55-1.51]$ or 0.85 [95\% CI, 0.49-1.47], respectively) (Additional files 1 and 2). The number of patients transfused with RBCs in the ICU tended to be higher in the liberal transfusion group than in the restrictive transfusion group (pooled OR, 9.94; 95\% CI, 0.39-250.88), although there was no significant difference, possibly due to wide distribution (Fig. 3). Moreover, there were no significant differences in the use of life support (ventilation, vasopressor use, or RRT) at 28 days of admission and the number of patients whom FFP or platelets were transfused during ICU stay between the two groups (Additional files 3, 4, 5, 6, and 7).

\section{Heterogeneity}

For the primary outcome of 28- or 30-day mortality, heterogeneity was observed among the studies $\left(I^{2}=61.0 \%\right.$, $\chi^{2}=5.13, p=0.08$ ) (Fig. 2). The evaluation of heterogeneity for other outcomes was described in forest plots (Fig. 3, Additional files 1, 2, 3, 4, 5, 6, and 7).

\section{Publication bias, risk of bias, and quality of evidence}

We also analyzed the presence of publication bias for the primary outcome. A visual inspection of the funnel plot and Egger's linear regression test showed no existence of publication bias in 28- or 30-day mortality $(p=$ 0.294). Regarding risk of bias, the blinding of participants and personnel was categorized as high risk in all three RCTs due to the nature of intervention (Figs. 4 and 5). For the effect of liberal versus restrictive blood transfusion strategy on the primary outcome, the quality of evidence was rated as low. The grade was lowered by 2 points due to a major inconsistency in heterogeneity and indirectness of the studies such as presence of different populations of patients. The summary of evidences is detailed in Table 2.

\section{Discussion}

To our knowledge, this study is the first systematic review and meta-analysis of RCTs investigating the effect of liberal versus restrictive RBC transfusion strategies on mortality in sepsis or septic shock patients. Although this meta-analysis included only three RCTs, the results suggested that the liberal strategy of RBC transfusion (with a hemoglobin threshold of 9 or $10 \mathrm{~g} / \mathrm{dL}$ ) failed to show any improvement in short-term (28- or 30-day) mortality in sepsis or septic shock patients, compared to the restrictive strategy (with a hemoglobin threshold of $7 \mathrm{~g} / \mathrm{dL}$ ).

Several studies have been conducted to determine the optimal blood transfusion threshold that would be the most beneficial to patient outcomes [16]. Hebert et al. conducted an RCT involving critically ill patients to compare the 30-day mortality rate between the liberal transfusion group (with a hemoglobin threshold of $10 \mathrm{~g} /$ $\mathrm{dL}$ ) and restrictive transfusion group (with a hemoglobin threshold of $7 \mathrm{~g} / \mathrm{dL}$ ) (TRICC trial) [15]. They found no significant difference in outcome between the two strategies and, thus, recommended the use of the restrictive transfusion strategy in critically ill patients. However, the subgroup analysis of this study also raised the possibility that the suggested blood transfusion threshold could differ due to different diseases and patient populations. In fact, the very recent 2018 Frankfurt Consensus Conference on patient blood management strongly recommended the use of the restrictive $\mathrm{RBC}$ transfusion threshold in critically ill but clinically stable intensive care patients and in patients undergoing cardiac surgery; however, use of the restrictive RBC transfusion threshold was not clearly recommended in patients with hip fracture and cardiovascular diseases or other risk factors as 
Table 1 Detail of included studies

\begin{tabular}{|c|c|c|c|}
\hline & TRICOP & TRISS & TRICC \\
\hline First author, year & Bergamin, 2017 [14] & Holst, 2014 [8] & Hebert, 1999 [15] \\
\hline Country & Brazil & $\begin{array}{l}\text { Denmark, Sweden, } \\
\text { Norway Finland }\end{array}$ & Canada \\
\hline No of site & 1 & 32 & 25 \\
\hline Inclusion period & 2012-2014 & $2011-2013$ & 1994-1997 \\
\hline No of patients & 300 & 998 & 218 (subgroup) \\
\hline Type of patients & $\begin{array}{l}\text { Cancer patients with septic } \\
\text { shock (ฏ18 years old) }\end{array}$ & $\begin{array}{l}\text { Patients with septic shock } \\
(\geqq 18 \text { years old })\end{array}$ & $\begin{array}{l}\text { Patients with severe infection or } \\
\text { septic shock ( } \geqq 16 \text { years old) }\end{array}$ \\
\hline \multicolumn{4}{|l|}{ Source of infection [liberal (\%) vs restrictive (\%)] } \\
\hline Lungs & 69 vs 61 & 52.2 vs 53.2 & \\
\hline Abdomen & 13 vs 17 & 39.9 vs 41.0 & Unknown \\
\hline Urinary tract & 9 vs 5 & 12.3 vs 11.6 & \\
\hline Other & 9 vs 17 & 21.4 vs 21.8 & \\
\hline \multicolumn{4}{|l|}{ Exclusion criteria (yes: excluded, no: not excluded) } \\
\hline Life-threating/uncontrolled bleeding & Yes & Yes & Yes \\
\hline Acute myocardial ischemia & No & Yes & No \\
\hline Admission after cardiac surgery & No & No & Yes \\
\hline Hematologic cancer & Yes & No & No \\
\hline Acute burn injury & No & Yes & No \\
\hline End-stage renal disease & Yes & No & No \\
\hline Pregnancy & No & No & Yes \\
\hline Anticoagulation therapy & Yes & No & No \\
\hline Withdrawal from active therapy & Yes & Yes & Yes \\
\hline $\begin{array}{l}\text { Hemoglobin threshold [liberal }(\mathrm{g} / \mathrm{dL}) \text { vs } \\
\text { restrictive }(\mathrm{g} / \mathrm{dL})]\end{array}$ & $<9$ vs $<7$ & $<9$ vs $<7$ & $<10$ vs $<7$ \\
\hline \multirow{2}{*}{$\begin{array}{l}\text { Severity of patients (SOFA score) [median } \\
\text { (interquartile range)] }\end{array}$} & Liberal; 6 (5-9) & Liberal; 10 (8-12) & Unknown \\
\hline & Restrictive; 7 (5-9) & Restrictive; 10 (8-12) & \\
\hline \multirow{2}{*}{$\begin{array}{l}\text { Timing of randomization after ICU admission } \\
\text { (h) [median (interquartile range)] }\end{array}$} & \multirow[t]{2}{*}{ Within $6 \mathrm{~h}$} & Liberal; 20 (7-43) & Within $72 \mathrm{~h}$ \\
\hline & & Restrictive; 23 (7-50) & \\
\hline Intervention period & ICU stay & ICU stay & ICU stay \\
\hline Leukodepletion & Yes & Yes & No \\
\hline \multirow[t]{5}{*}{ Outcomes } & Mortality (28, 60, 90 days) & Mortality $(28,60,90$ days $)$ & Mortality (30 days) \\
\hline & Ischemic events & Ischemic events & \\
\hline & Severe adverse reactions & Severe adverse reactions & \\
\hline & Use of life support at 28 days & $\begin{array}{l}\text { Use of life support at } 28 \\
\text { days }\end{array}$ & \\
\hline & $\begin{array}{l}\text { Number of patients transfused } \\
\text { in the ICU }\end{array}$ & $\begin{array}{l}\text { Number of patients } \\
\text { transfused in the ICU }\end{array}$ & \\
\hline
\end{tabular}

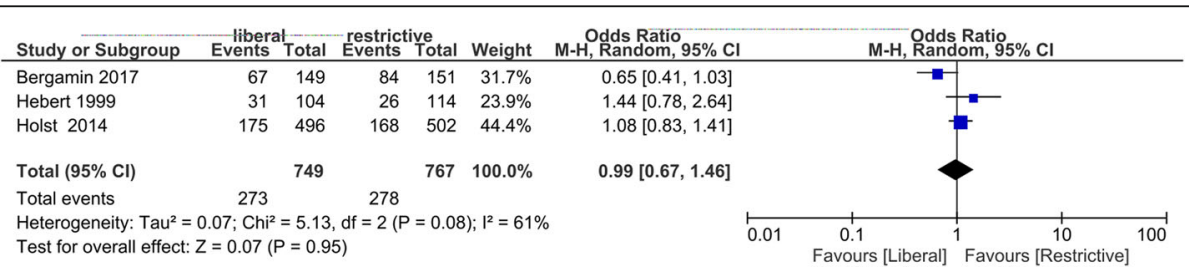

Fig. 2 Forest plot of the 28- or 30-day mortality compared between liberal and restrictive blood transfusion strategy in sepsis or septic shock 


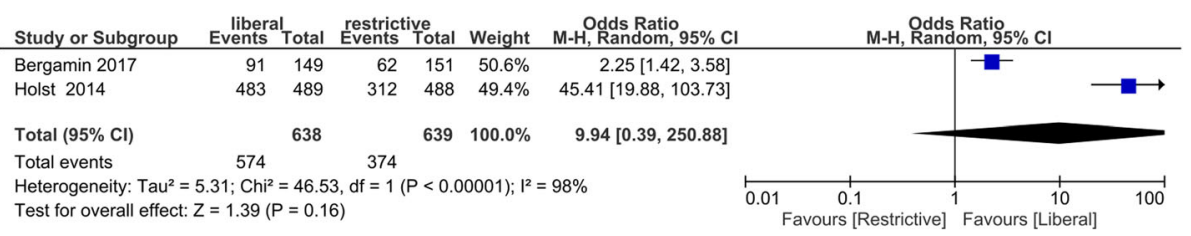

Fig. 3 Forest plot of the number of patients transfused with RBC in the ICU in comparison between liberal and restrictive blood transfusion strategy

well as in hemodynamically stable patients with acute gastrointestinal bleeding (conditional recommendation) [17]. Apparently, recent clinical trials investigating the hemoglobin threshold for transfusion have been more focused on narrow and specific populations [18-22].

Numerous cohort studies have been conducted on blood transfusion thresholds in patients with sepsis or septic shock. A systematic review of 12 cohort studies, including 9 studies focusing on mortality rates, has confirmed the safety of restrictive transfusion [6]. However, no meta-analysis has been performed of randomized trials on the hemoglobin threshold for RBC transfusion in this population due to the lack of RCTs. Similar to the abovementioned systematic review of cohort studies, our meta-analysis of RCTs revealed no differences in clinically important outcomes, such as 28- or 30-day

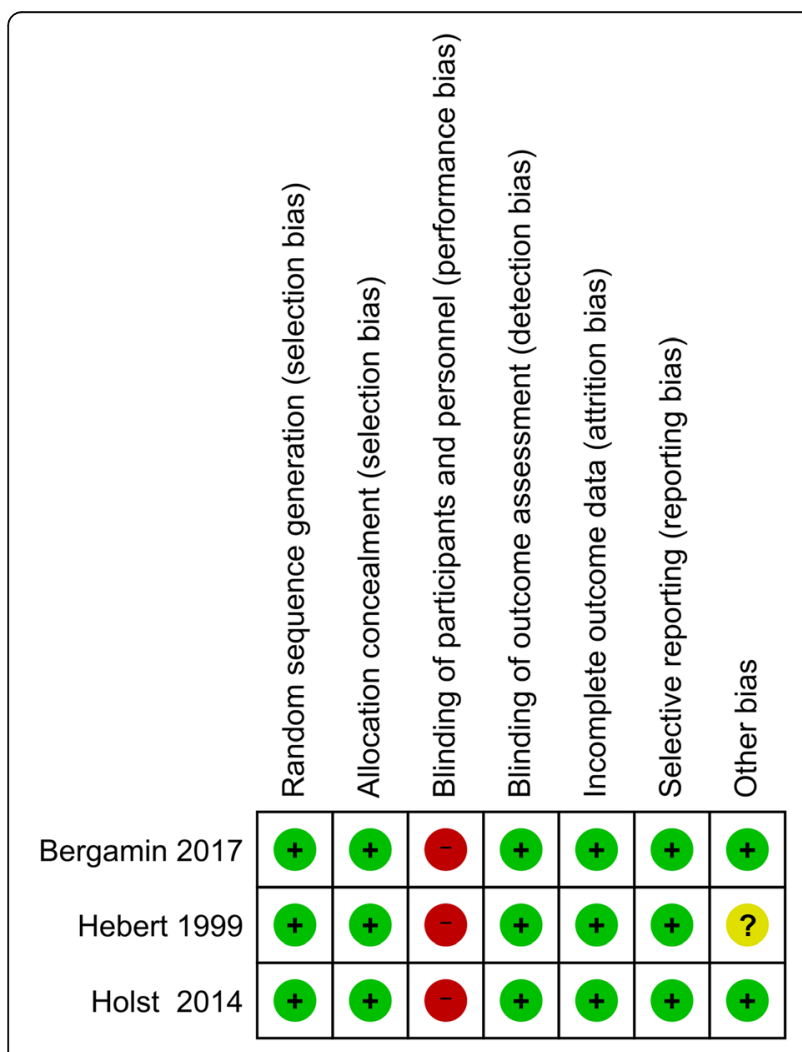

Fig. 4 Risk of bias summary mortality, between the liberal and restrictive blood transfusion strategies. Furthermore, we could not show any differences in secondary outcomes, such as 60- or 90day mortality, use of life support (ventilation, vasopressor use, or RRT) at 28 days of admission, and number of patients who underwent FFP or platelet transfusion during ICU stay between the two strategies; however, only two RCTs were included for the analysis of secondary outcomes. Considering the limited availability of blood supply for transfusions, we recommend the use of the restrictive transfusion strategy over the liberal transfusion strategy in sepsis or septic shock patients.

Caution is required while interpreting our findings. The inclusion criteria for sepsis patients in each RCT analyzed were diverse. Particularly, the participants of the most recent RCT (TRICOP) were cancer patients with septic shock. In fact, the mortality rate was higher in this single-centered trial than in the other two trials. This study showed opposing results with respect to primary outcome, with a lower 28-day mortality rate in the liberal transfusion group, implying that the threshold of RBC blood transfusion in sepsis patients could differ according to the underlying medical conditions or diseases. Moreover, exclusion criteria also differed among the three RCTs. For example, acute myocardial ischemia patients were excluded from the TRISS trial but not from the TRICOP and TRICC trials, even though use of a restrictive transfusion threshold of $<80 \mathrm{~g} / \mathrm{L}$ may not be safe in patients with underlying acute coronary syndrome or chronic cardiovascular disease [23]. As sepsis patients often show several complications, the patient's background should be carefully considered while selecting between the liberal and restrictive strategies for blood transfusion. This heterogeneity in the comorbidities of sepsis patients also presents problems in transfusion trials where fixed interventions can cause practice misalignment in diverse populations. Further sepsis-related trials in carefully selected populations are anticipated.

\section{Limitations of the study}

This meta-analysis has several limitations. First, only three RCTs were analyzed for the primary outcome and only two RCTs were analyzed for secondary outcomes. 


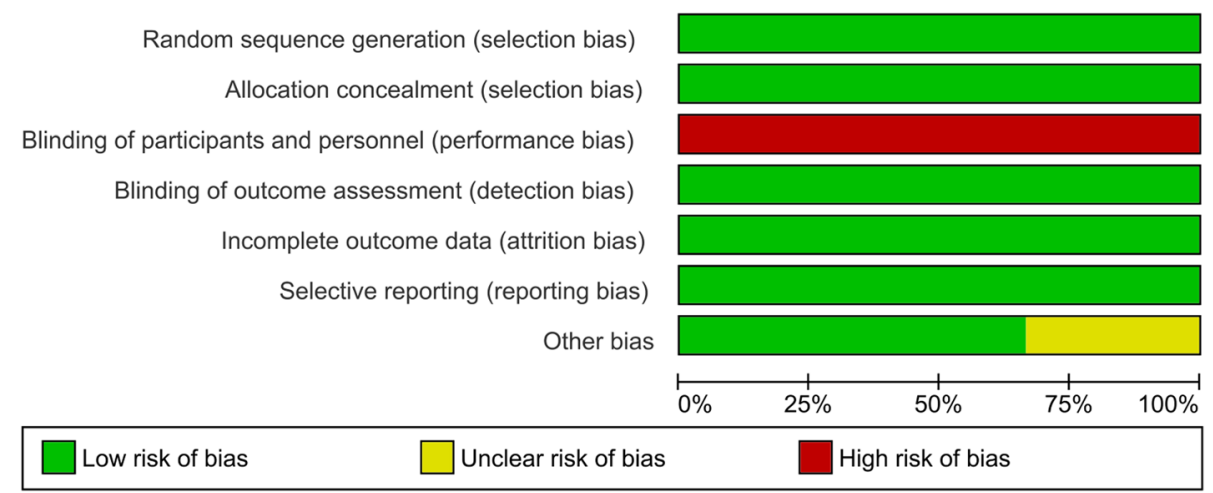

Fig. 5 Risk of bias graph

However, meta-analyses of too many low-quality studies can also cause bias. Thus, well-designed RCTs are required in the future to support our findings. Second, the participants and healthcare staff were aware of the group assignment in all included RCTs, resulting in potential performance bias. It was impossible to conceal the group assignment because of the characteristics of the intervention. However, this bias is unlikely to affect the results due to the use of stratified randomization and objective endpoints as well as the use of multicentered

Table 2 Summary of findings

\begin{tabular}{|c|c|c|c|c|c|}
\hline \multirow[t]{2}{*}{ Outcomes } & \multicolumn{2}{|c|}{ Anticipated absolute effects ${ }^{*}(95 \% \mathrm{Cl})$} & \multirow{2}{*}{$\begin{array}{l}\text { Relative effect: } \\
\text { OR }(95 \% \mathrm{Cl})\end{array}$} & \multirow{2}{*}{$\begin{array}{l}\text { No. of } \\
\text { participants } \\
\text { (no. of } \\
\text { studies) }\end{array}$} & \multirow{2}{*}{$\begin{array}{l}\text { Certainty } \\
\text { of } \\
\text { evidence } \\
\text { (GRADE) }\end{array}$} \\
\hline & $\begin{array}{l}\text { Risk with restrictive } \mathrm{RBC} \\
\text { transfusion }\end{array}$ & $\begin{array}{l}\text { Risk with liberal RBC } \\
\text { transfusion }\end{array}$ & & & \\
\hline 28- or 30-day mortality & 362 per 1000 & 360 per $1000(276-454)$ & $0.99(0.67-1.46)$ & $\begin{array}{l}1516(3 \\
\text { RCTs) }\end{array}$ & $\operatorname{Low}^{a, b}$ \\
\hline 60-day mortality & 452 per 1000 & 429 per $1000(312-554)$ & $0.91(0.55-1.51)$ & $\begin{array}{l}1298(2 \\
\text { RCTs) }\end{array}$ & $\operatorname{Low}^{\mathrm{b}, \mathrm{c}}$ \\
\hline 90-day mortality & 493 per 1000 & 453 per 1000 (323-588) & $0.85(0.49-1.47)$ & $\begin{array}{l}1298(2 \\
\text { RCTs) }\end{array}$ & $\operatorname{Low}^{\mathrm{b}, \mathrm{d}}$ \\
\hline $\begin{array}{l}\text { No. of patients transfused with } \mathrm{RBC} \text { in the } \\
\text { ICU }\end{array}$ & 585 per 1000 & 933 per 1000 (355-997) & $\begin{array}{l}9.94(0.39- \\
250.88)\end{array}$ & $\begin{array}{l}1277(2 \\
\mathrm{RCTs})\end{array}$ & $\operatorname{Low}^{\mathrm{b}, \mathrm{e}}$ \\
\hline Ventilation use at 28 days & 146 per 1000 & 147 per $1000(81-250)$ & $1.01(0.52-1.96)$ & $\begin{array}{l}1277(2 \\
\text { RCTs) }\end{array}$ & $\operatorname{Low}^{\mathrm{b}, \mathrm{f}}$ \\
\hline Vasopressor use at 28 days & 66 per 1000 & 69 per $1000(28-161)$ & $1.06(0.41-2.72)$ & $\begin{array}{l}1277(2 \\
\text { RCTs) }\end{array}$ & $\operatorname{Low}^{\mathrm{b}, \mathrm{g}}$ \\
\hline RRT at 28 days & 66 per 1000 & 64 per 1000 (41-99) & $0.97(0.60-1.57)$ & $\begin{array}{l}1277(2 \\
\text { RCTs) }\end{array}$ & Moderate $^{b}$ \\
\hline $\begin{array}{l}\text { No. of patients transfused with FFP in the } \\
\text { ICU }\end{array}$ & 186 per 1000 & 205 per 1000 (163-257) & $1.13(0.85-1.51)$ & $\begin{array}{l}1277(2 \\
\text { RCTs) }\end{array}$ & Moderate $^{b}$ \\
\hline $\begin{array}{l}\text { No. of patients transfused with platelet in } \\
\text { the ICU }\end{array}$ & 146 per 1000 & 165 per 1000 (120-221) & $1.16(0.80-1.67)$ & $\begin{array}{l}1277(2 \\
\text { RCTs) }\end{array}$ & Moderate $^{b}$ \\
\hline
\end{tabular}

Grades of evidence according to the Grading of Recommendations Assessment, Development and Evaluation (GRADE) working group

High certainty: We are very confident that the true effect lies close to that of the estimate of the effect

Moderate certainty: We are moderately confident in the effect estimate. The true effect is likely to be close to the estimate of the effect, but there is a possibility that it is substantially different

Low certainty: Our confidence in the effect estimate is limited: The true effect may be substantially different from the estimate of the effect

Very low certainty: We have very little confidence in the effect estimate. The true effect is likely to be substantially different from the estimate of the effect

*The risk in the intervention group (and its $95 \%$ confidence interval $[\mathrm{Cl}]$ ) was based on the assumed risk in the comparison group and the relative effect of the intervention (and its $95 \% \mathrm{Cl}$ )

a Heterogeneity was observed among the studies $\left(I^{2}=61.0 \%, X^{2}=5.13, p=0.08\right)$. Downgraded by 1

${ }^{\mathrm{b}}$ Indirectness such as different populations of patients was observed in the studies. Downgraded by 1

${ }^{c}$ Heterogeneity was observed among the studies $\left(I^{2}=72.0 \%, X^{2}=3.63, p=0.06\right)$. Downgraded by 1

${ }^{\mathrm{d}}$ Heterogeneity was observed among the studies $\left(I^{2}=77.0 \%, X^{2}=4.27, p=0.04\right.$.) Downgraded by 1

eterogeneity was observed among the studies $\left(I^{2}=98.0 \%, X^{2}=46.53, p<0.01\right)$. Downgraded by 1

${ }^{f}$ Heterogeneity was observed among the studies $\left(I^{2}=75.0 \%, X^{2}=4.04, p=0.04\right)$. Downgraded by 1

${ }^{9}$ Heterogeneity was observed among the studies $\left(I^{2}=71.0 \%, X^{2}=3.49, p=0.06\right)$. Downgraded by 1

$R B C$ red blood cell, $O R$ odds ratio, $R C T$ randomized controlled trial, ICU intensive care unit, $R R T$ renal replacement therapy, FFP fresh frozen plasma 
participants in two of the three RCTs. Third, the leukodepletion status of RBCs before transfusion was different among trials. As leukodepletion of blood products could reduce several complications of transfusion, such as alloimmunization of human leukocyte antigen (HLA), cytomegalovirus transmission, and recurrent febrile nonhemolytic transfusion reaction, this process could influence the outcome [24]. Finally, we observed some heterogeneities among the included trials, such as timing of randomization, inclusion and exclusion criteria, and source of sepsis. Even though systematic reviews and meta-analyses are considered to be powerful tools for solving research questions, heterogeneity is the one of the weaknesses of these statistical methods $[25,26]$.

\section{Conclusions}

Based on the findings of this meta-analysis, we could not show any difference in short-term (28- or 30-day) mortality between the liberal RBC transfusion strategy with a hemoglobin threshold of 9 or $10 \mathrm{~g} / \mathrm{dL}$ and the restrictive strategy with a hemoglobin threshold of $7 \mathrm{~g} / \mathrm{dL}$ in sepsis or septic shock patients. We therefore recommend the restrictive transfusion strategy from the perspective of cost and resource saving; however, coexisting diseases such as cancer or cardiovascular disease in sepsis patients should be carefully considered. "Sepsis" or "septic shock" might still be too large as a category in deciding the best hemoglobin threshold for blood transfusion.

\section{Additional files}

Additional file 1: Forest plot of the 60-day mortality in comparison between liberal and restrictive blood transfusion strategy in sepsis or septic shock. (TIFF $10644 \mathrm{~kb}$ )

Additional file 2: Forest plot of the 90-day mortality in comparison between liberal and restrictive blood transfusion strategy in sepsis or septic shock. (TIFF $10644 \mathrm{~kb}$ )

Additional file 3: Forest plot of the ventilation use at 28 days of admission in comparison between liberal and restrictive blood transfusion strategy in sepsis or septic shock. (TIFF $10644 \mathrm{~kb}$ )

Additional file 4: Forest plot of the vasopressor use at 28 days of admission in comparison between liberal and restrictive blood transfusion strategy in sepsis or septic shock. (TIFF $10644 \mathrm{~kb}$ )

Additional file 5: Forest plot of the renal replacement therapy at 28 days of admission in comparison between liberal and restrictive blood transfusion strategy in sepsis or septic shock. (TIFF $10644 \mathrm{~kb}$ )

Additional file 6: Forest plot of the number of patients whom FFP was transfused during ICU stay in comparison between liberal and restrictive blood transfusion strategy in sepsis or septic shock. (TIFF $5987 \mathrm{~kb}$ )

Additional file 7: Forest plot of the number of patients whom platelets was transfused during ICU stay in comparison between liberal and restrictive blood transfusion strategy in sepsis or septic shock. (TIFF 5987 kb)

\section{Abbreviations}

Cl: Confidence interval; HLA: Human leukocyte antigen; ICU: Intensive care unit; OR: Odds ratio; RBC: Red blood cell; RCT: Randomized controlled trial; RRT: Renal replacement therapy

\section{Acknowledgements}

We would like to thank Editage (www.editage.jp) for English language editing.

\section{Author's contributions}

YH and YK designated this study. YH, MY, and YK identified the studies entered in the meta-analysis and analyzed the data. YH drafted the manuscript. All authors interpreted the data and discussed the manuscript. All authors read and approved the final manuscript.

\section{Funding}

Dr. Hirano is currently receiving a grant (\#17K11593) from Japan Society for the Promotion of Science (JSPS).

\section{Availability of data and materials}

The data and material used for this meta-analysis are contained in the references.

Ethics approval and consent to participate

Not applicable.

\section{Consent for publication}

Not applicable.

\section{Competing interests}

The authors declare that they have no competing interests.

Received: 16 March 2019 Accepted: 16 July 2019

Published online: 25 July 2019

References

1. Chan YL, Han ST, Li CH, Wu CC, Chen KF. Transfusion of red blood cells to patients with sepsis. Int J Mol Sci. 2017;18(9).

2. Docherty $A B$, Turgeon AF, Walsh TS. Best practice in critical care: anaemia in acute and critical illness. Transfus Med. 2018;28(2):181-9.

3. Amato A, Pescatori M. Perioperative blood transfusions for the recurrence of colorectal cancer. Cochrane Database Syst Rev. 2006:(1):Cd005033.

4. Cata JP, Wang H, Gottumukkala V, Reuben J, Sessler DI. Inflammatory response, immunosuppression, and cancer recurrence after perioperative blood transfusions. Br J Anaesth. 2013;110(5):690-701.

5. Raghavan M, Marik PE. Anemia, allogenic blood transfusion, and immunomodulation in the critically ill. Chest. 2005;127(1):295-307.

6. Dupuis C, Sonneville R, Adrie C, Gros A, Darmon M, Bouadma L, Timsit JF. Impact of transfusion on patients with sepsis admitted in intensive care unit: a systematic review and meta-analysis. Ann Intensive Care. 2017;7(1):5.

7. Rhodes A, Evans LE, Alhazzani W, Levy MM, Antonelli M, Ferrer R, Kumar A Sevransky JE, Sprung CL, Nunnally ME, et al. Surviving Sepsis Campaign: International Guidelines for Management of Sepsis and Septic Shock: 2016. Crit Care Med. 2017:45(3):486-552.

8. Holst LB, Haase N, Wetterslev J, Wernerman J, Guttormsen AB, Karlsson S, Johansson PI, Aneman A, Vang ML, Winding R, et al. Lower versus higher hemoglobin threshold for transfusion in septic shock. N Engl J Med. 2014; 371(15):1381-91.

9. Yealy DM, Kellum JA, Huang DT, Barnato AE, Weissfeld LA, Pike F, Terndrup T, Wang HE, Hou PC, LoVecchio F, et al. A randomized trial of protocolbased care for early septic shock. N Engl J Med. 2014;370(18):1683-93.

10. Singer M, Deutschman CS, Seymour CW, Shankar-Hari M, Annane D, Bauer M, Bellomo R, Bernard GR, Chiche JD, Coopersmith CM, et al. The Third International Consensus Definitions for Sepsis and Septic Shock (Sepsis-3). Jama. 2016;315(8):801-10.

11. Higgins JP, Altman DG, Gotzsche PC, Juni P, Moher D, Oxman AD, Savovic J, Schulz KF, Weeks L, Sterne JA. The Cochrane Collaboration's tool for assessing risk of bias in randomised trials. BMJ. 2011;343:d5928.

12. Guyatt G, Oxman AD, Akl EA, Kunz R, Vist G, Brozek J, Norris S, Falck-Ytter $Y$, Glasziou P, DeBeer $H$, et al. GRADE guidelines: 1. Introduction-GRADE evidence profiles and summary of findings tables. J Clin Epidemiol. 2011; 64(4):383-94.

13. Egger M, Davey Smith G, Schneider M, Minder C. Bias in meta-analysis detected by a simple, graphical test. BMJ. 1997;315(7109):629-34.

14. Bergamin FS, Almeida JP, Landoni G, Galas F, Fukushima JT, Fominskiy E, Park CHL, Osawa EA, Diz MPE, Oliveira GQ, et al. Liberal versus restrictive 
transfusion strategy in critically ill oncologic patients: the transfusion requirements in critically ill oncologic patients randomized controlled trial. Crit Care Med. 2017;45(5):766-73.

15. Hebert PC, Wells G, Blajchman MA, Marshall J, Martin C, Pagliarello G, Tweeddale M, Schweitzer I, Yetisir E. A multicenter, randomized, controlled clinical trial of transfusion requirements in critical care. Transfusion Requirements in Critical Care Investigators, Canadian Critical Care Trials Group. N Engl J Med. 1999;340(6):409-17.

16. Carson JL, Stanworth SJ, Roubinian N, Fergusson DA, Triulzi D, Doree C, Hebert PC. Transfusion thresholds and other strategies for guiding allogeneic red blood cell transfusion. Cochrane Database Syst Rev. 2016;10: Cd002042.

17. Mueller MM, Van Remoortel H, Meybohm P, Aranko K, Aubron C, Burger R, Carson JL, Cichutek K, De Buck E, Devine D, et al. Patient blood management: recommendations from the 2018 Frankfurt Consensus Conference. Jama. 2019;321(10):983-97.

18. Carson JL, Terrin ML, Noveck H, Sanders DW, Chaitman BR, Rhoads GG, Nemo G, Dragert K, Beaupre L, Hildebrand K, et al. Liberal or restrictive transfusion in high-risk patients after hip surgery. N Engl J Med. 2011; 365(26):2453-62.

19. English SW, Fergusson D, Chasse M, Turgeon AF, Lauzier F, Griesdale D, Algird A, Kramer A, Tinmouth A, Lum C, et al. Aneurysmal subarachnoid hemorrhage-red blood cell transfusion and outcome (SAHaRA): a pilot randomised controlled trial protocol. BMJ Open. 2016;6(12):e012623.

20. Jairath V, Kahan BC, Gray A, Dore CJ, Mora A, James MW, Stanley AJ, Everett SM, Bailey AA, Dallal $H$, et al. Restrictive versus liberal blood transfusion for acute upper gastrointestinal bleeding (TRIGGER): a pragmatic, open-label, cluster randomised feasibility trial. Lancet. 2015;386(9989):137-44.

21. Mazer CD, Whitlock RP, Fergusson DA, Hall J, Belley-Cote E, Connolly K, Khanykin B, Gregory AJ, de Medicis E, McGuinness S, et al. Restrictive or liberal red-cell transfusion for cardiac surgery. N Engl J Med. 2017;377(22): 2133-44.

22. Palmieri TL, JHt H, Arnoldo B, Peck M, Potenza B, Cochran A, King BT, Dominic W, Cartotto R, Bhavsar D, et al. Transfusion Requirement in Burn Care Evaluation (TRIBE): a multicenter randomized prospective trial of blood transfusion in major burn injury. Ann Surg. 2017;266(4):595-602.

23. Docherty AB, O'Donnell R, Brunskill S, Trivella M, Doree C, Holst L, Parker M, Gregersen M, Pinheiro de Almeida J, Walsh TS, et al. Effect of restrictive versus liberal transfusion strategies on outcomes in patients with cardiovascular disease in a non-cardiac surgery setting: systematic review and meta-analysis. BMJ. 2016;352:11351.

24. Dzik WH. Leukoreduction of blood components. Curr Opin Hematol. 2002; 9(6):521-6.

25. Bailar JC 3rd. The promise and problems of meta-analysis. N Engl J Med. 1997;337(8):559-61.

26. Gopalakrishnan S, Ganeshkumar P. Systematic reviews and meta-analysis: understanding the best evidence in primary healthcare. J Fam Med Prim Care. 2013;2(1):9-14

\section{Publisher's Note}

Springer Nature remains neutral with regard to jurisdictional claims in published maps and institutional affiliations.

Ready to submit your research? Choose BMC and benefit from:

- fast, convenient online submission

- thorough peer review by experienced researchers in your field

- rapid publication on acceptance

- support for research data, including large and complex data types

- gold Open Access which fosters wider collaboration and increased citations

- maximum visibility for your research: over $100 \mathrm{M}$ website views per year

At $\mathrm{BMC}$, research is always in progress.

Learn more biomedcentral.com/submissions 